\title{
EL PRINCIPIO DE PROGRESIVIDAD EN EL ORDENAMIENTO CONSTITUCIONAL MEXICANO*
}

\author{
THE PROGRESSION PRINCIPLE IN THE MEXICAN \\ CONSTITUTIONAL ORDER
}

\author{
Roberto Gustavo MANCILla CASTRO**
}

\begin{abstract}
RESUMEN: El propósito del presente trabajo es hacer un estudio comprensivo de las aplicaciones del principio de progresividad en materia constitucional, buscando mostrarle al lector no sólo cuestiones básicas del mismo, sino posibles aplicaciones novedosas. Esto se debe a que con el advenimiento de la reforma de derechos humanos y de amparo de 2011, no se ha determinado completamente la utilidad y los parámetros del antes mencionado principio, de forma tal que el presente artículo puede proveer a las autoridades un referente útil.
\end{abstract}

Palabras clave: principio de progresividad, orden constitucional, Constitución Política de los Estados Unidos Mexicanos, interpretación constitucional, mutación constitucional.
ABSTRACT: The purpose of this paper is to do a comprehensive study of the applications of the progressive principle in constitutional law, seeking to show the reader not only basic aspects of it, but also possible innovative applications. This is because with the advent of the 2011 human rights and amparo suit constitutional amendment, the usefulness and parameters of this principle are yet to be determined. This article can provide a useful reference to legal authorities.

Descriptors: progression principle, constitutional order, Political Constitution of the Mexican United States, constitutional interpretation, constitutional mutation.

* Dedicado a mi querido amigo José Carlos Guerra Aguilera.

** Licenciado en derecho por el Instituto Tecnológico y de Estudios Superiores de Monterrey; maestro y doctor en derecho por la Universidad de California en Berkeley. 


\section{INTRODUCCIÓN}

La reforma constitucional en materia de derechos humanos y de amparo trajo consigo un cambio de paradigma, no sólo en la forma de entender el derecho constitucional mexicano, sino también sobre cómo aplicar la ley suprema nacional. Uno de los principios más importantes que se mencionan en la reforma es el de progresividad: los derechos puedan aumentar, pero no disminuir.

Sin embargo, cabe preguntar ¿existía el principio de progresividad antes de la reforma de 2011? Y de ser así, ¿cuál era su alcance? El propósito del presente artículo es determinar de forma exhaustiva los alcances del principio de progresividad y sus aplicaciones en el derecho constitucional. Este artículo surge también como seguimiento a los temas tratados en mi libro Derecho adjetivo constitucional, entre los que figuran: aplicación constitucional, principio de progresividad y bloque de la constitucionalidad. ${ }^{1}$

El análisis comienza por determinar los alcances de este principio al ver cómo el ámbito jurídico, es decir, la naturaleza de la norma que lo contiene (Constitución, tratado internacional), lo influencia. Asimismo, se trata de ver si la actividad jurídica a la que se aplica (interpretación y mutación jurídica) lo afecta. Una vez visto esto, se tratará de ver las particularidades de la interpretación y la mutación constitucional, además de analizar el alcance actual del principio de progresividad por medio de la interpretación de los artículos primero y veintinueve, así como analizar el artículo primero, previo a la reforma, para determinar la existencia del principio.

Una vez realizado este análisis estándar, se determinará el alcance de este principio en dos aspectos que van más allá de la zona de confort del derecho constitucional mexicano. El primero de éstos conjunta la interpretación junto con la mutación constitucional para determinar la existencia de un ordenamiento constitucional, lo que significa la retroalimentación de la aplicación de la Constitución (consistente en la interpretación y mutación dichas) al texto de la misma. Siendo el principio de progresividad uno de sus principales rectores, al proveer de una guía a este proceso, además de ser un límite competencial de las autoridades que ejerzan estas actividades.

El segundo consiste en determinar la conexión que existe entre la progresividad y el bloque de la constitucionalidad — la asignación de jerarquía

1 Mancilla Castro, Roberto Gustavo, Derecho adjetivo constitucional, México, Novum, 2012. 
constitucional a normas secundarias o documentos jurídicos relevantespara ver si resulta aplicable en materia federal. Para este análisis se realizará primeramente un análisis teórico del bloque de la constitucionalidad y sus antecedentes. Después se procederá a ver cómo se ha aplicado en el ámbito local, con el Distrito Federal y Nuevo León como ejemplos. Por último, se realizará una interpretación del artículo primero constitucional para demostrar cómo podría incorporarse en el ordenamiento jurídico mexicano.

\section{CONCEPTO Y PARÁMETROS DE APLICACIÓN}

El principio de progresividad surge en el derecho internacional, y tiene entre sus primeros antecedentes al Pacto Internacional de Derechos Civiles y Políticos (1966) y a la Convención Interamericana de Derechos Humanos (1969). A pesar de esto, existía un antecedente doctrinario, pues algunos teóricos (como Mario L. Deveali) referían principios, por ejemplo el de "progresión racional", como las bases del desarrollo del derecho laboral. ${ }^{2}$

El principio de progresividad es un principio interpretativo que establece que los derechos no pueden disminuir, por lo cual, al sólo poder aumentar, progresan gradualmente. Es importante notar que la naturaleza de este principio depende del ámbito en el que esté incorporado y de la actividad para la que se aplique.

El primer aspecto consiste en el área del derecho a la cual se esté aplicando el principio (derecho internacional y constitucional, por ejemplo), y el segundo aspecto a la actividad jurídica que se esté realizando (interpretación o mutación jurídica).

\section{La progresividad en los distintos ámbitos jurídicos}

El ámbito en que se incorpore el principio determina en parte cómo se debe entender el mismo. Por ejemplo, si se encuentra incorporado a un tratado internacional, debe utilizarse como un principio de derecho internacional público, y al aplicarse debe verse la jerarquía que tienen los tratados inter-

2 Gialdino, Ronaldo E., Dignidad, justicia social, principio de progresividad y núcleo duro interno. Aportes del derecho internacional de los derechos humanos al derecho del trabajo y al de la seguridad social, http://www.laboralistas.com.ar/blog/Principio_ de_progresividad_de_los_Derechos_Gialdino.doc. 
nacionales en el ordenamiento jurídico, puesto que en algunos países los tratados se encuentran por debajo de la Constitución, pero en otros tienen una jerarquía similar o incluso superior.

$\mathrm{Si}$, en cambio, se encuentra incorporado a la norma suprema, debe interpretarse como un principio constitucional, haciendo valerse en conjunción al principio de supremacía constitucional en los instrumentos de control constitucional. Por su carácter accesorio, la finalidad de este principio es aquella de los derechos humanos que ayuda a aplicar, es decir, busca la materialización de la dignidad humana, al establecer límites a las actuaciones de los Estados, o en su caso a los poderes constituidos de los mismos.

\section{La progresividad en la interpretación jurídica}

Interpretar consiste en esclarecer o declarar el sentido de un texto, y la interpretación jurídica se centra en la norma. Carmona Tinoco la entiende como "la actividad por la cual se determina el sentido de las expresiones del derecho". ${ }^{3}$ De la Cueva lo complementa diciendo que "debe proponerse desentrañar el contenido de cada norma, esto es, determinar en qué consiste el mandamiento, cuál es el deber que impone, su alcance o extensión y sus limitaciones, y cuál es la medida de la sanción que debe imponerse al contraventor". ${ }^{4}$

En su artículo 29, inciso b), la Convención Interamericana de Derechos Humanos dispone:

Artículo 29. Normas de Interpretación.

Ninguna disposición de la presente Convención puede ser interpretada en el sentido de:

b) limitar el goce y ejercicio de cualquier derecho o libertad que pueda estar reconocido de acuerdo con las leyes de cualquiera de los Estados Partes o de acuerdo con otra convención en que sea parte uno de dichos Estados.

3 Carmona Tinoco, Jorge Ulises, La interpretación judicial constitucional, México, UNAM, Instituto de Investigaciones Jurídicas-Comisión Nacional de Derechos Humanos, 1996, p. 21.

4 Cueva, Mario de la, Teoría de la Constitución, 2a. ed., México, Porrúa, 2008, p. 67. 
Tomando esto en cuenta, el principio de progresividad implica que las interpretaciones a las leyes deben hacerse tomando en consecuencia a las realizadas anteriormente, buscando no disminuir las determinaciones hechas sobre el parámetro y la sustancia de los derechos interpretados. Debe reiterarse que la naturaleza misma de la actividad interpretativa cambia de acuerdo a la rama jurídica en que se encuentre, es decir, la interpretación de la Constitución y de los tratados internacionales siguen una dinámica especifica.

Al interpretar una norma jurídica, dicha actividad retroalimenta la norma existente y se integra a la misma. El principio de progresividad sirve como complemento de la interpretación jurídica porque establece un estándar de interpretación y al mismo tiempo es un límite competencial del intérprete.

\section{La progresividad en la mutación jurídica}

Por mutación jurídica debe entenderse todo cambio realizado a la norma jurídica fuera de los procedimientos para la misma. Este término se deriva del de mutación constitucional, el cual ha sido estudiado por la doctrina constitucional alemana desde el siglo XIX y que será detallada en los temas venideros.

Se utiliza el término mutación, y no el de integración, porque el primero resulta más amplio, al entender que se puede cambiar el contenido de la ley en contra de su espíritu, mientras que la integración sólo puede atender a la resolución de lagunas jurídicas, nunca en perjuicio del sistema jurídico. En este entendido, la mutación jurídica es el género, y la integración, la especie.

El Pacto Internacional de Derechos Civiles y Políticos en su artículo 5.2 establece la progresividad de la forma siguiente:

\section{Artículo 5}

2. No podrá admitirse restricción o menoscabo de ninguno de los derechos humanos fundamentales reconocidos o vigentes en un Estado Parte en virtud de leyes, convenciones, reglamentos o costumbres, so pretexto de que el presente Pacto no los reconoce o los reconoce en menor grado.

Esta cita da a entender que una norma puede ser mutada por medio de legislación (y también por la actividad jurisprudencial), siempre y cuando 
no se incurra en el menoscabo de derechos antes referido. De la misma forma que la interpretación jurídica, los cambios informales al ordenamiento jurídico, realizados por cualquier vía (jurisprudencia, legislación o actos administrativos de efectos generales), se retroalimentan a la norma.

\section{EL PRINCIPIO DE PROGRESIVIDAD EN LA INTERPRETACIÓN Y MUTACIÓN CONSTITUCIONAL}

La particularidad de la interpretación constitucional consiste en la naturaleza de la norma que interpreta, ya que las leyes ordinarias carecen de la naturaleza rígida e impositiva del ordenamiento constitucional y de su carácter de suprema. La interpretación constitucional es una rama de la interpretación jurídica que se centra en analizar la norma o normas que tienen jerarquía suprema en un sistema jurídico. Quedan comprendidas en este parámetro la Constitución y cualquier norma que tenga rango constitucional (bloque de la constitucionalidad).

La mutación constitucional es definida por Jellinek como: "aquella modificación de la Constitución que deja indemne su texto, sin cambiarlo formalmente, que se produce por hechos que no tienen que ir acompañados por la intención o consciencia de tal mutación". ${ }^{5}$ Puede inferirse que la mutación es una característica de la rigidez en las Constituciones, pero no es necesariamente un problema. Sólo cuando la mutación se encuentra en contradicción con la Constitución, puede considerarse una patología jurídica.

La interpretación busca determinar el alcance de una norma, mientras que la mutación busca realizar un cambio en una norma sin que medie una reforma, el cual puede no utilizarse para resolver una laguna. Algo que ambas tienen en común es que tanto la interpretación del derecho, como la mutación del mismo, pueden usarse con finalidades distintas al bienestar común. ${ }^{6}$

5 Dau-Lin, Hsu, Mutación de la Constitución, trad. de Pablo Lucas Verdú y Cristian Forster, Oñati, Instituto Vasco de la Administración Pública, 1998, p. 13.

6 Véase a Sagüés, Néstor Pedro, La interpretación judicial de la Constitución, $2 \mathrm{a}$. ed., Buenos Aires, Lexis Nexis-Abeledo Perrot, 2006, en la manipulación constitucional. Asimismo a Hsu Dau-Lin, en cuanto a mutaciones constitucionales contradictorias del contenido constitucional. 
En el texto actual de la Constitución Política de los Estados Unidos Mexicanos, el principio de progresividad se encuentra contenido dentro del artículo primero, el cual establece lo siguiente:

En los Estados Unidos Mexicanos todas las personas gozarán de los derechos humanos reconocidos en esta Constitución y en los tratados internacionales de los que el Estado Mexicano sea parte, así como de las garantías para su protección, cuyo ejercicio no podrá restringirse ni suspenderse, salvo en los casos y bajo las condiciones que esta Constitución establece.

Todas las autoridades, en el ámbito de sus competencias, tienen la obligación de promover, respetar, proteger y garantizar los derechos humanos de conformidad con los principios de universalidad, interdependencia, indivisibilidad y progresividad. En consecuencia, el Estado deberá prevenir, investigar, sancionar y reparar las violaciones a los derechos humanos, en los términos que establezca la ley. [Énfasis añadido]

El principio de progresividad en este artículo se encuentra contenido en dos partes. En la primera se habla de que tanto los derechos como su ejercicio no pueden restringirse ni suspenderse salvo en los casos previstos por la Constitución. En la segunda parte, se hace mención expresa de la misma.

Podría parecer redundante que se mencione la sustancia y después se nombre el mismo principio, pero el texto podría interpretarse de la siguiente forma para evitar la misma: la primera parte se puede tener como el contenido mínimo del principio de progresividad, mientras que la mención del mismo principio da lugar a que al determinar su alcance, mediante la aplicación constitucional, se pueda ampliar más allá del contenido mínimo.

En su texto original, la Constitución Política de los Estados Unidos Mexicanos, expedida el 5 de febrero de 1917, establece el principio de progresividad de la forma siguiente: "En los Estados Unidos Mexicanos todo individuo gozará de las garantías que otorga esta Constitución, las cuales no podrán restringirse ni suspenderse, sino en los casos y con las condiciones que ella misma establece".

En este entendido, la Constitución mexicana siempre ha tenido dentro de su seno el principio de progresividad, incluso antes de la existencia de los tratados internacionales referidos con anterioridad, solamente que nunca había sido mencionado como tal. 
Retomando el análisis del artículo primero, el mismo establece la suspensión y restricción de los derechos en los casos establecidos por el texto constitucional, específicamente, el artículo 29, que aunque no es referido de modo explícito, es el único que hace mención de la disminución o restricción de derechos, y lo hace en los términos siguientes:

En los casos de invasión, perturbación grave de la paz pública, o de cualquier otro que ponga a la sociedad en grave peligro o conflicto, solamente el Presidente de los Estados Unidos Mexicanos, de acuerdo con los titulares de las Secretarías de Estado y la Procuraduría General de la República y con la aprobación del Congreso de la Unión o de la Comisión Permanente cuando aquél no estuviere reunido, podrá restringir o suspender en todo el país o en lugar determinado el ejercicio de los derechos y las garantías que fuesen obstáculo para hacer frente, rápida y fácilmente a la situación; pero deberá hacerlo por un tiempo limitado, por medio de prevenciones generales y sin que la restricción o suspensión se contraiga a determinada persona. Si la restricción o suspensión tuviese lugar hallándose el Congreso reunido, éste concederá las autorizaciones que estime necesarias para que el Ejecutivo haga frente a la situación; pero si se verificase en tiempo de receso, se convocará de inmediato al Congreso para que las acuerde.

En los decretos que se expidan, no podrá restringirse ni suspenderse el ejercicio de los derechos a la no discriminación, al reconocimiento de la personalidad jurídica, a la vida, a la integridad personal, a la protección a la familia, al nombre, a la nacionalidad; los derechos de la niñez; los derechos políticos; las libertades de pensamiento, conciencia y de profesar creencia religiosa alguna; el principio de legalidad y retroactividad; la prohibición de la pena de muerte; la prohibición de la esclavitud y la servidumbre; la prohibición de la desaparición forzada y la tortura; ni las garantías judiciales indispensables para la protección de tales derechos.

La restricción o suspensión del ejercicio de los derechos y garantías debe estar fundada y motivada en los términos establecidos por esta Constitución y ser proporcional al peligro a que se hace frente, observando en todo momento los principios de legalidad, racionalidad, proclamación, publicidad y no discriminación.

Cuando se ponga fin a la restricción o suspensión del ejercicio de los derechos y garantías, bien sea por cumplirse el plazo o porque así lo decrete el Congreso, todas las medidas legales y administrativas adoptadas durante su vigencia quedarán sin efecto de forma inmediata. El Ejecutivo no podrá hacer observaciones al decreto mediante el cual el Congreso revoque la restricción o suspensión. 
Los decretos expedidos por el Ejecutivo durante la restricción o suspensión, serán revisados de oficio e inmediatamente por la Suprema Corte de Justicia de la Nación, la que deberá pronunciarse con la mayor prontitud sobre su constitucionalidad y validez. [Énfasis añadido]

Al determinar el artículo 29 los límites del principio de progresividad, termina por establecer los alcances del mismo en el ordenamiento constitucional mexicano. Esto lo hace, no sólo marcando las circunstancias y los procedimientos para la restricción y disminución de derechos humanos, sino también al definir cuales derechos son irreducibles, así como los requerimientos mínimos de legalidad para la validez jurídica del decreto de disminución y el órgano competente para conocer la constitucionalidad y validez del mismo.

Aplicando la progresividad a la interpretación y la mutación constitucional, se puede decir que la ampliación de los derechos constitucionales que sean consagrados por la jurisprudencia no puede ser disminuida por actos posteriores.

El principio de progresividad en el ámbito constitucional se transforma en un principio de evolución constitucional, si se entiende lo que establece el artículo 16 de la Declaración de los Derechos del Hombre y del Ciudadano, que dice: "Toda sociedad en la cual no esté establecida la garantía de los derechos, ni determinada la separación de los poderes, carece de Constitución". ${ }^{7}$ Se tiene entonces, que el principio de progresividad en una Constitución es un principio de autopreservación, pues busca evitar que ésta se deje de aplicar y por ende caiga en la obsolescencia.

\section{LA PROGRESIVIDAD COMO PRINCIPIO ESTRUCTURADOR DEL ORDENAMIENTO CONSTITUCIONAL}

En su notable estudio The Endurance of National Constitutions, Elkins, Ginsburg y Melton enuncian tres factores que ayudan a una Constitución a durar: inclusión, especificidad y flexibilidad. ${ }^{8}$ Este último factor es similar

7 Declaración de los Derechos del Hombre y el Ciudadano, http://www.elysee. fr/elyseelespagnol/las_instituciones/los_textos_fundadores/la_declaracion_de_los_ derechos_del_hombre/la_declaracion_de_los_derechos_del_hombre.21654.html.

8 Elkins, Zachary et al., The Endurance of National Constitutions, Nueva York, Cambridge University Press, 2009, pp. 65, 78. 
a la mutación, pero la diferencia radica en que la flexibilidad incluye a la interpretación, la mutación y la resistencia constitucional.

Cuando existe una tensión entre Constitución y realidad, la mutación surge como una forma de liberar presiones, cambiando el sentido de la Constitución, pero dejándola aplicable, de lo contrario habría una ruptura en el orden constitucional y un riesgo de colapso en el mismo.

Correctamente aplicada, la mutación constitucional se puede entender como un mecanismo para liberar las presiones que una Constitución debe resistir: el paso del tiempo, cambios internos y externos e interacciones entre los órganos constituidos. Elkins y compañía lo entienden de esta forma al justificar la flexibilidad en una Ley Suprema. ${ }^{9}$ Del origen de las mutaciones constitucionales, Pedro de Vega dice: ${ }^{10}$

Por otro lado, las modificaciones no formales de la Constitución proceden de fuentes distintas. Unas veces emanan de órganos estatales, y adquieren el carácter de verdaderos actos jurídicos, ya sean de naturaleza normativa (leyes, reglamentos), ya sean de naturaleza jurisdiccional (básicamente las sentencias de los Tribunales Constitucionales). Otras veces derivan de simples prácticas políticas que, o no sobrepasan su condición de hechos, quedando convertidas en normas de naturaleza político social (convenciones), o aspiran a convertirse en auténticos hechos jurídicos (costumbres).

Interpretando a De Vega, y tomando en cuenta de lo que Da Silva ${ }^{11}$ dice de él, la mutación constitucional puede clasificarse de la forma siguiente:

a) Mutación por medio de normas.

b) Mutación por medio de actos jurisdiccionales (sentencias y jurisprudencia).

c) Mutación por medio de costumbre.

d) Mutación por medio de convenciones constitucionales.

9 Ibidem, p. 81.

10 Vega, Pedro de, La reforma constitucional y la problemática del poder constituyente, 6a. reimpr., Madrid, Tecnos, 2007, p. 189.

11 Da Silva, José Alfonso, "Mutaciones constitucionales", Cuestiones Constitucionales, núm. 1, julio-diciembre de 1999. http://www.juridicas.unam.mx/publica/rev/cconst/ cont/1/tes/tes 1.htm\#N31. 
Algo que debe tomarse en cuenta es que cualquier tipo de mutación puede usarse para violar la Constitución. De Vega no toma en cuenta el potencial para violación cuando habla de las fuentes de la mutación. Respecto de los límites de la mutación, Da Silva dice que el conflicto entre realidad y norma puede ser resuelto: "a) o por enmienda constitucional, b) o por la prevalencia de la norma sobre el hecho por decisión judicial firme". ${ }^{12}$ Por su parte, Pedro de Vega dice: ${ }^{13}$

Mientras la tensión siempre latente entre lo factico y lo normativo no se presenta en términos de conflicto e incompatibilidad manifiesta, las mutaciones constitucionales pueden coexistir con el principio de supremacía constitucional, sin que éste sufra ningún deterioro importante. El problema de los límites de la mutación comienza cuando la tensión entre facticidad y normatividad se convierte social, política y jurídicamente en un conflicto que pone en peligro la misma noción de supremacía. Es entonces cuando aparece como única alternativa posible la de, o bien convertir la practica convencional (la mutación) en norma a través de la reforma, o bien, negar el valor jurídico, en nombre de la legalidad existente, de la mutación.

Es importante notar que la mutación no es una actividad interpretativa, pues no busca determinar el significado de la Constitución, sino que busca cambiarla para aliviar la presión de un estrés exógeno, aunque como ha dicho Dau-Lin, hay mutaciones que pueden cancelar el contenido de la norma suprema. La integración constitucional implica cambiar el sentido de la Constitución sin enmendar el texto, pero esto no implica que sea sinónimo de la mutación.

La mutación es todo cambio benéfico o dañino a la Constitución sin que medie una enmienda, mientras que la integración busca adaptar la norma suprema a los estímulos externos, por lo cual puede decirse que la mutación es la especie, y la integración el género. Tanto la mutación como la integración pueden ser realizadas por cualquier órgano de gobierno (sin importar a qué poder pertenezcan) a través de normas (leyes o reglamentos, costumbres, pactos políticos y jurisprudencia). La integración como sector de la mutación constitucional puede hacerse al usar la Constitución o al

13 Vega, Pedro de, op. cit., p. 215. 
usar fuentes externas para colmar la laguna, pero siempre bajo el marco que establece el razonamiento jurídico.

Francisco Tomás y Valiente aporta la noción de resistencia constitucional en su artículo "La resistencia constitucional y los valores": 14

- Puede entenderse como la adaptabilidad a la dinámica política.

- Es la capacidad de ser interpretada en una forma flexible, y hasta cierto punto cambiar en función de nuevos problemas, sensibilidades y exigencias.

- También es la resistencia a la reforma constitucional, haciéndola innecesaria.

- Consiste en asimilar las diferentes expectativas políticas no opuestas frontalmente al texto y a su sentido sistemático.

- Una Constitución tiene resistencia si es capaz de producir un acoplamiento entre la realidad normativa y la siempre cambiante realidad política, es decir, es la capacidad de asumir mutaciones.

La resistencia, como la mutación, es una característica de las Constituciones rígidas y es la capacidad que una Constitución posee para adaptarse al cambio. Sea una interpretación que expande su contenido o la asimilación de la integración que cambia su significado. Es la capacidad de una Constitución de responder a presiones externas.

La resistencia constitucional es un concepto que media entre la interpretación y la mutación constitucional: interpretación y resistencia son similares en la sustancia porque son formas que tiene una Constitución de lidiar con las distintas circunstancias que influencian su duración; sin embargo, difieren en que la interpretación puede expandir su significado siempre y cuando la norma se lo permita, pero la naturaleza de la resistencia es la adaptabilidad al cambio y aunque se traslapa en algunas cosas con la interpretación, puede prescindir de ella y acercarse a la integración. La resistencia es característica de las Constituciones rígidas, pero la interpretación no lo es, puesto que una Constitución flexible, como cualquier ley, puede ser interpretada.

Respecto de la intercepción de interpretación y resistencia, vale la pena mencionar un tipo de interpretación constitucional que Sagüés denomina

14 Tomás y Valiente, Francisco, La resistencia constitucional y los valores, http:// www.cervantesvirtual.com/servlet/SirveObras/public/01361620824573839199024/ cuaderno15/volII/doxa15_08.pdf?portal=4. 
interpretación mutativa, la cual es un proceso interpretativo que admite la existencia de una mutación. ${ }^{15} \mathrm{El}$ citado autor divide este tipo de interpretación en dos tipos: interpretación mutativa promotora de la mutación, ${ }^{16}$ la cual da origen a la mutación, e interpretación putativa reconociente de la mutación, ${ }^{17}$ que consiste en la verificación y recepción de una mutación hecha por la costumbre y la admite como un cambio respecto de la Constitución formal.

Estos conceptos no se encuentran tanto en el campo de la interpretación jurídica, puesto que no buscan determinar el significado de la Constitución, sino dar paso a la integración. Sin embargo, no son mutaciones constitucionales, por lo que estos actos se encuentran dentro de la resistencia constitucional, que es un concepto intermedio que llena el espacio que existe entre interpretación y mutación.

Tanto la mutación (integración) como la resistencia tienen su origen en una Constitución rígida, es decir, una que dificulta el proceso de reforma o que lo hace imposible. Ambos conceptos reaccionan ante el problema de una laguna que hace peligrar el orden constitucional, sin embargo, la resistencia también es afín a la interpretación por lo que permite determinar y expandir el significado de una Constitución sin presentar un cambio de lleno. Si esto no fuera así, la resistencia no sería distinguible de la mutación.

Los conceptos de interpretación, resistencia y mutación se encuentran relacionados con la capacidad de una Constitución de durar y ser aplicada, aunque difieren respecto del método utilizado para lograr estos propósitos, puesto que una interpretación expande el significado, la mutación lo cambia y la resistencia media entre ambos con una naturaleza propia.

La idea de la flexibilidad de una Constitución propuesta por Elkins, Ginsburg y Melton comprende los conceptos de interpretación, resistencia y mutación. La flexibilidad es la capacidad del texto de la Constitución de adaptarse e incorporar estímulos externos a su estructura, es decir, expandir su significado o cambiarlo. La interpretación, resistencia y mutación son variaciones del significado de una Constitución cuando responden a un estímulo externo, sea político, económico, jurídico, el paso del tiempo, entre otros imaginables. Es decir, son grados de flexibilidad constitucional.

Cuando la norma constitucional se aplica, este acto resulta en una interpretación, una mutación o una interpretación mutativa, las cuales se re-

15

16

17 Idem 
troalimentan a la norma. A esto se le puede denominar ciclo de interacción constitucional, es decir, son todos aquellos actos que resultan en el acercamiento o alejamiento entre la Constitución como proyecto de realidad y la realidad manifestada a través del Estado.

Cuando la aplicación de la Constitución resulta en una degeneración de su contenido, se habla de un ciclo interactivo involutivo, el cual puede ser considerado como una patología constitucional. Cuando la Constitución se muta para llenar una laguna que está provocando una crisis o cuando existe una interpretación o mutación que ensanchan el contenido de la Ley Suprema, se tiene que la interacción constitucional es constructiva o evolutiva. La interacción constitucional se puede describir a través del siguiente esquema:

Esquema. Interacciones constitucionales

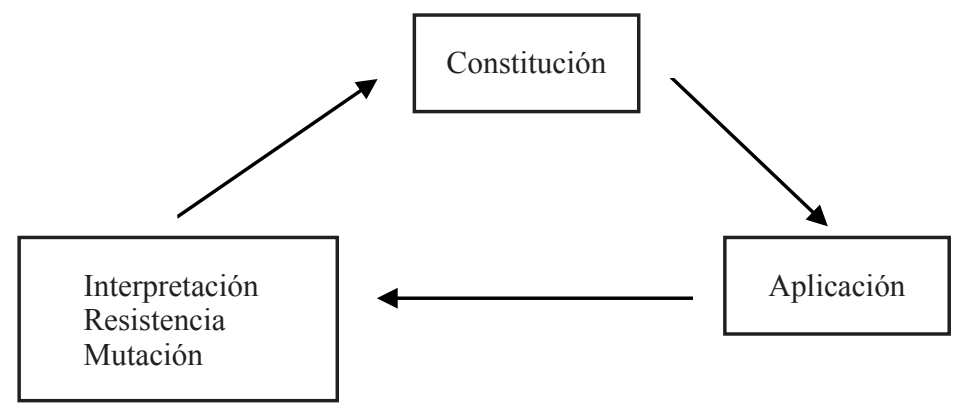

Se puede entender por ordenamiento constitucional a la retroalimentación constante que es producto de las interacciones que resultan de la aplicación de la ley suprema. El ordenamiento constitucional está construido a partir de la norma suprema, la cual se aplica, interpreta, muta y adapta (idóneamente) a las circunstancias por medio del cambio o de la ampliación de su contenido.

A diferencia de una Constitución, que es producto de una deliberación de fuerzas políticas, el orden constitucional es sistemático y total. Esto se debe a que el Constituyente crea lagunas al no poder preveer todas las circunstancias o no ponerse de acuerdo en ciertos temas, cuestiones que permiten a generaciones futuras suplir estas deficiencias por medio de la aplicación de la ley suprema. 
El principio de progresividad es una de las bases primordiales del ordenamiento constitucional mexicano, puesto que da una pauta para las interacciones constitucionales, poniendo como límite competencial a toda autoridad que aplique la Constitución el hecho de que los derechos pueden aumentar, pero no disminuir.

Tanto las interpretaciones como las mutaciones que resulten de la aplicación constitucional deben aumentar los derechos constitucionales, de lo contrario podrían ser consideradas inconstitucionales por contravenir el principio de progresividad como parte del espíritu constitucional.

\section{EL BLOQUE DE LA CONSTITUCIONALIDAD}

\section{Definición y naturaleza}

Ayala Corao define al bloque de la constitucionalidad como los "instrumentos jurídicos que tienen el valor y el rango constitucional, o lo que equivale a estar contenidos en la propia jerarquía de la Constitución". ${ }^{18} \mathrm{El}$ instrumento antes mencionado es una extensión de la norma suprema en el sentido material, puesto que se le interpreta y se le aplica como una disposición constitucional, aunque su contenido es diferente al de la carta magna.

La naturaleza jurídico-política de la Constitución se distingue de la puramente jurídica de las leyes que dimanan de la misma, puesto que la primera impone y las segundas regulan. ${ }^{19}$ De esta manera se entiende que las normas integrantes del bloque de la constitucionalidad no son formalmente constitucionales, porque no se encuentran dentro del corpus de la Constitución.

\section{Origen}

La actual Constitución de la Quinta República Francesa, promulgada en 1958, establece un Tribunal Constitucional que se denomina Consejo Constitucional (Conseil Constitutionnel), que inicialmente estaba conceptualizado como un árbitro competencial, puesto que la ley suprema limita

18 Ayala Corao, Carlos M., La jerarquía constitucional de los tratados relativos a derechos humanos y sus consecuencias, México, Fundap, 2003, p. 66.

19 Córdova, Arnaldo, "La Constitución no es ley”, La Jornada, 8 de julio de 2007. 
la competencia del legislador al establecer una serie de áreas exclusivas en las que el presidente debe normar con reglamentos.

Sin embargo, en la decisión número 71-44 DC del 16 de julio de 1971, el Consejo Constitucional se estableció como guardián de los derechos de los particulares, al declarar inconstitucional una ley que acotaba el derecho de asociación.

En esta decisión, también se estableció el bloque de la constitucionalidad, al reconocerle valor constitucional al preámbulo de la Constitución de 1958, al de la Constitución de 1956 y a los principios fundamentales reconocidos por las leyes de la República. Al respecto, el segundo considerando de esta decisión establece lo siguiente:

2. Considerando que hay un número de principios fundamentales reconocidos por las leyes de la Republica y solemnemente reafirmados por el preámbulo de la Constitución, ha lugar a situar el principio de libertad de asociación; que es la base de las disposiciones generales de la ley del primero de julio de 1901 relativa al contrato de asociación (traducción del autor)... ${ }^{20}$

\section{Incorporación de una ley en el bloque de la constitucionalidad.} Consecuencias para el instrumento

Cuando se incorpora una ley dentro del bloque de la constitucionalidad, ésta sufre diversos cambios que es conveniente analizar. Por formar parte de la carta magna deben determinarse para el bloque de la constitucionalidad los mismos principios que se aplican a la Constitución en general. Respecto de su proceso de reforma, se debe de seguir el proceso de reforma complicada que se tiene para la norma suprema.

Una ley incorporada al bloque de la constitucionalidad es defendible por medio de los mecanismos de control constitucional que la ley consagra y su interpretación compete solamente al Poder Judicial, que es el intérprete de la Constitución. Los derechos que consagra dicha ley a los particulares son garantías individuales o sociales (dependiendo de su naturaleza) y se pueden defender por medio del juicio de amparo.

20 Conseil Constitutionnel, Décision no. 71-44, DC du 16 juillet 1971, http://www. conseil-constitutionnel.fr/conseil-constitutionnel/francais/les-decisions/depuis-1958/ decisions-par-date/1971/71-44-dc/decision-n-71-44-dc-du-16-juillet-1971.7217.html. 
Aplican los mismos principios interpretativos de la Constitución, y de existir pugna con las normas de la contradicción, se tiene que interpretar como excepción a la regla general.

Góngora Mera, al analizar el bloque de la constitucionalidad en Argentina, el cual se compone de tratados internacionales en materia de derechos humanos, enumera los efectos jurídicos del bloque. No todos son aplicables a la idea general del bloque de la constitucionalidad, por lo que se adaptarán algunos y otros se removerán de la lista. Dicho esto, los efectos jurídicos del bloque de la constitucionalidad es el siguiente: ${ }^{21}$

a) Aplicabilidad directa de los instrumentos que hacen parte del bloque.

b) Inconstitucionalidad de las actuaciones estatales contrarias a los derechos reconocidos en el bloque.

c) Expansión de la labor interpretativa de los jueces.

d) Irradiación del poder normativo del bloque a ordenamientos internos.

e) Modificación de competencias en el orden interno.

f) Normas que se incorporan al bloque de la constitucionalidad.

No existe un tipo específico de normas que se deban incorporar al bloque de la constitucionalidad, cualquier norma puede ser incorporada, incluso si no pertenece al orden jurídico interno, tal es el caso de la incorporación de tratados internacionales.

El que se incorporen unas u otras depende de la realidad social y de la historia y cultura jurídica de un país.

Gongora Mera aborda el tema:

Cada tribunal ha entendido por "bloque" el conjunto de normas que tienen jerarquía constitucional en el ordenamiento jurídico; la diferencia entre ellos radica en el tipo de normas que incorporan dentro del bloque. Por ejemplo: para el Conseil d'Etat, el bloque está compuesto por la Constitución, la Declaración de Derechos de 1789, el preámbulo de la Constitución de 1946 y los principios fundamentales de las leyes de la República; para el Tribunal Constitucional español, hacen parte del bloque los estatutos de las comunidades autónomas y algunas leyes orgánicas; en Colombia se incluyen no sólo

21 Góngora Mera, Manuel Eduardo, "El bloque de constitucionalidad en Argentina y su relevancia en la lucha contra la impunidad", Centro de Derechos Humanos de Nuremberg, http://www.menschenrechte.org/beitraege/lateinamerika/Argentina_bloque_y_am nistia.pdf. 
los tratados internacionales de derechos humanos, sino además las subreglas jurisprudenciales de la Corte Constitucional. ${ }^{22}$

\section{EL BLOQUE DE LA CONSTITUCIONALIDAD EN EL ORDENAMIENTO JURÍDICO MEXICANO}

\section{A nivel local}

En el ordenamiento jurídico mexicano se pueden encontrar claros ejemplos del bloque de la constitucionalidad en el Distrito Federal y en el estado de Nuevo León. En el primer caso, se creó por virtud de jurisprudencia de la Suprema Corte; en el segundo, por reconocimiento expreso de la Constitución local.

La Suprema Corte de Justicia de la Nación, en la tesis jurisprudencial P. /J. 18/2007 consagra un bloque de la constitucionalidad consistente en el Estatuto de Gobierno y la Constitución general de la Republica en materia electoral. A continuación se transcribe la tesis en comento:

Estatuto de Gobierno del Distrito Federal. Junto con la ConstiTUCIÓN POLÍTICA DE LOS ESTADOS UNIDOS MEXICANOS INTEGRA BLOQUE DE CONSTITUCIONALIDAD EN MATERIA ELECTORAL. Los artículos 122, apartado A, fracción II y apartado $C$, base primera, fracción $V$, inciso f), $y$ 116, fracción IV, incisos b) al i), de la Constitución Política de los Estados Unidos Mexicanos, y las normas que en particular establezca el legislador federal en el Estatuto de Gobierno del Distrito Federal, integran un bloque de constitucionalidad en materia electoral para esta entidad. Lo anterior es así, ya que el artículo 122, apartado C, base primera, fracción V, inciso f), de la Constitución federal, señala que las disposiciones que rijan en materia electoral en el Distrito Federal deben sujetarse al Estatuto de Gobierno del Distrito Federal, el cual tomará en cuenta los principios establecidos en los incisos b) al i) de la fracción IV del artículo 116 constitucional; lo anterior, porque el fundamento del Estatuto de Gobierno del Distrito Federal es el indicado artículo 122, y el respeto a la jerarquía constitucional es un requisito para la validez de dicho Estatuto, por lo que, el respeto a lo dispuesto por 
él, es un requisito de validez para las actuaciones de todas las autoridades del Distrito Federal. [Énfasis añadido]

En la Constitución del estado de Nuevo León, el bloque de la constitucionalidad se encuentra depositado en el artículo 152 de la Constitución Política del Estado de Nuevo León, el cual dice que "las leyes a que se refieren los artículos 45, 63 fracción XIII, 94, 95 y 118, son constitucionales y en su reforma guardarán las mismas reglas que en las de cualquier artículo de la Constitución, pudiendo ser discutidas y votadas en el mismo periodo en que sean propuestas, si así lo acordare el Congreso". A continuación se hace un listado de las leyes ya dichas por el antes mencionado dispositivo constitucional, las cuales guardan jerarquía constitucional:

a) Ley Electoral de Nuevo León (artículo 45 de la Constitución de Nuevo León).

b) Ley Orgánica del Órgano de Fiscalización Superior del Estado de Nuevo León (artículo 63, fracción XIII).

c) Ley Orgánica del Poder Judicial del Estado de Nuevo León (artículo 94).

d) Ley Reglamentaria del Artículo 95 de la Constitución del Estado de Nuevo León.

e) Ley Orgánica de la Administración Pública Municipal (artículo 118).

Las leyes derivadas del artículo 152, por encontrarse en el bloque de la constitucionalidad local, están sujetas a la protección que por medio de los instrumentos constitucionales consagra el artículo 95 constitucional, y su proceso de reforma es complicado.

La vaga redacción de este numeral, puede dar lugar a que en su interpretación surjan una de dos instituciones que son completamente diferentes: las leyes orgánicas constitucionales o el bloque de la constitucionalidad.

Ambas instituciones se pueden interpretar del texto del dispositivo 152. Podría pensarse que cuando se habla de "leyes constitucionales" que tienen un proceso de reforma similar al de la Constitución local, se está hablando de leyes orgánicas constitucionales - aquellas que tienen un proceso complicado de reforma, pero que no poseen jerarquía constitucional-, sin embargo, también se puede interpretar como una investidura de grado constitucional a las leyes mencionadas, aun cuando se confiera facultad al Congreso de acordar la discusión y la votación de las leyes dentro del mismo periodo legislativo. 
El problema de la vaguedad de este precepto constitucional reside en el hecho de que no hay un señalamiento expreso de la jerarquía que guardan las leyes mencionadas con respecto a la Constitución y las leyes ordinarias.

\section{A nivel federal}

En los Estados Unidos Mexicanos, el bloque de la constitucionalidad se encuentra establecido de la forma siguiente: 1) tratados internacionales en materia de derechos humanos; 2) interpretaciones que expandan los derechos humanos (principio de la interpretación más amplia, principio de progresividad y principio pro homine); 3) La expansión de los derechos humanos realizada por medio de legislación secundaria (principio de progresividad). Todo lo anterior se encuentra contenido en el artículo 1o. de nuestra ley suprema.

La primera expansión a la Constitución se da cuando el artículo 10. establece el goce de derechos humanos reconocidos en la misma y en los tratados internacionales de los que el Estado sea parte y garantiza una protección irrestricta a los mismos, salvo lo determinado en el numeral 29 de la misma. La segunda expansión se da cuando se establece en los párrafos segundo y tercero la obligación de todas las autoridades dentro del ámbito de su competencia de garantizar y proteger los derechos humanos contenidos en la Constitución o en los tratados y de interpretarlos de la forma más amplia y favorable. Con tal fin se transcribe el texto:

Artículo 1o. [...]

Las normas relativas a los derechos humanos se interpretarán de conformidad con esta Constitución y con los tratados internacionales de la materia favoreciendo en todo tiempo a las personas la protección más amplia.

Todas las autoridades, en el ámbito de sus competencias, tienen la obligación de promover, respetar, proteger y garantizar los derechos humanos de conformidad con los principios de universalidad, interdependencia, indivisibilidad y progresividad. En consecuencia, el Estado deberá prevenir, investigar, sancionar y reparar las violaciones a los derechos humanos, en los términos que establezca la ley.

El principio de progresividad resulta aplicable tanto a derechos consagrados en la Constitución como en las normas secundarias, y los derechos 
establecidos en esta normativa infraconstitucional pueden presentar una expansión a aquellos que atañen a la carta magna o pueden tener una existencia autónoma. Cuando se aplica el principio de progresividad a una norma secundaria que expande la norma suprema, se da un cambio en su naturaleza, puesto que si resulta imposible su disminución o remoción - salvo que se pondere otro principio constitucional con mayor prioridad en un caso específico - se tiene entonces que posee un grado de supremacía similar en el fondo, aunque no en la forma, al dispositivo constitucional que complementa.

Se tiene entonces que toda autoridad que haga una interpretación dentro de su ámbito competencial, que haga una expansión a los derechos humanos existentes y que de la misma resulten efectos generales, expande el bloque de la constitucionalidad. Esto incluye, por ejemplo, la participación del Ejecutivo y Legislativo en el proceso legislativo o la actividad jurisdiccional difusa o concreta que siente jurisprudencia, siempre y cuando se indique que se encuentran interpretando la Constitución. La tercera expansión resulta similar — pero no idéntica — a la segunda: cualquier norma general que resulte en una expansión de derechos humanos, sin que expresamente señale que se interpreta la Constitución.

Por último, el bloque de la constitucionalidad queda perfeccionado si se toma en cuenta el artículo 133 constitucional en relación a lo dicho en párrafos anteriores. Este numeral establece:

Artículo 133. Esta Constitución, las leyes del Congreso de la Unión que emanen de ella y todos los tratados que estén de acuerdo con la misma, celebrados y que se celebren por el Presidente de la República, con aprobación del Senado, serán la Ley Suprema de toda la Unión. Los jueces de cada estado se arreglarán a dicha Constitución, leyes y tratados, a pesar de las disposiciones en contrario que pueda haber en las constitucionales o leyes de los estados.

Este artículo constitucional establece una jerarquía normativa en dos niveles: 1) por un lado, al establecer que la Constitución, legislación secundaria y tratados "serán la Ley Suprema de toda la Unión", lo hace con respecto a la legislación de los Estados, es decir, la normativa federal es superior a la local; 2) por otro lado, dado el orden en que se enumeran, dentro de las leyes federales, la jerarquía es la siguiente: a) Constitución; b) legislación, y c) tratados. No obstante lo anterior, la Suprema Corte de Justicia de la Nación realizó la siguiente interpretación: 
TRATADOS INTERNACIONALES. SON PARTE INTEGRANTE DE LA LEY SUPREMA DE LA UNIÓN Y SE UBICAN JERÁRQUICAMENTE POR ENCIMA DE LAS LEYES GENERALES, FEDERALES Y LOCALES. INTERPRETACIÓN DEL ARTÍCULO 133 CONSTITUCIONAL. La interpretación sistemática del artículo 133 de la Constitución Política de los Estados Unidos Mexicanos permite identificar la existencia de un orden jurídico superior, de carácter nacional, integrado por la Constitución Federal, los tratados internacionales y las leyes generales. Asimismo, a partir de dicha interpretación, armonizada con los principios de derecho internacional dispersos en el texto constitucional, así como con las normas y premisas fundamentales de esa rama del derecho, se concluye que los tratados internacionales se ubican jerárquicamente abajo de la Constitución federal y por encima de las leyes generales, federales y locales, en la medida en que el Estado mexicano al suscribirlos, de conformidad con lo dispuesto en la Convención de Viena sobre el Derecho de los Tratados entre los Estados y Organizaciones Internacionales o entre Organizaciones Internacionales y, además, atendiendo al principio fundamental de derecho internacional consuetudinario pacta sunt servanda, contrae libremente obligaciones frente a la comunidad internacional que no pueden ser desconocidas invocando normas de derecho interno y cuyo incumplimiento supone, por lo demás, una responsabilidad de carácter internacional.

Amparo en revisión 120/2002. Mc. Cain México, S. A. de C. V. 13 de febrero de 2007. Mayoría de seis votos. Disidentes: José Ramón Cossío Díaz, Margarita Beatriz Luna Ramos, José Fernando Franco González Salas, José de Jesús Gudiño Pelayo y Juan N. Silva Meza. Ponente: Sergio Salvador Aguirre Anguiano. Secretarios: Andrea Zambrana Castañeda, Rafael Coello Cetina, Malkah Nobigrot Kleinman y Maura A. Sanabria Martínez.

El Tribunal Pleno, el veinte de marzo en curso, aprobó, con el número IX/2007, la tesis aislada que antecede. México, Distrito Federal, a veinte de marzo de dos mil siete.

En lo referente a jerarquía normativa, el artículo 133 constitucional choca con el artículo primero, puesto que en éste último se señala la prevalencia de los derechos humanos contenidos en la Constitución y los tratados internacionales. Para evitar esta incongruencia entre dispositivos constitucionales, y tomando en cuenta lo dicho por la Suprema Corte, podría hacerse la siguiente interpretación: 1) los derechos humanos contenidos en la Constitución, los tratados, y su expansión por medio de legislación secundaria, tienen grado constitucional; 2) cuando no se trate de derechos humanos, la 
jerarquía normativa se da de la siguiente forma: a) Constitución; b) tratados internacionales, y c) legislación secundaria.

\section{CONCLUSIONES}

Primera. La naturaleza del principio de progresividad es variable, pues depende de la actividad y del ámbito a los que se aplica.

Segunda. En materia constitucional, principio de progresividad es un límite competencial de las autoridades encargadas de hacer efectiva la Constitución. En ese entendido, las interpretaciones y mutaciones constitucionales deben estar limitadas por este principio.

Tercera. La Constitución, al aplicarse, interpretarse y mutarse, se convierte en un ordenamiento constitucional. El principio de progresividad es un principio depurador del ordenamiento constitucional, pues funciona como un principio de autopreservación.

Cuarta. En la Constitución mexicana, el principio de progresividad se encuentra contenido desde 1917, la reforma de 2011 no afecta su sustancia, pero determina su parámetro con exactitud por medio del artículo 29.

Quinta. El principio de progresividad resulta aplicable tanto a derechos consagrados en la Constitución como a normas secundarias y a derechos establecidos en normas secundarias.

Sexta. Cuando se aplica el principio de progresividad a una norma secundaria que expande la norma suprema, se da un cambio en su naturaleza, puesto que si resulta imposible su disminución o remoción, se tiene entonces que posee un grado de supremacía similar a la norma constitucional que complementa. Dicha norma secundaria pasa a formar parte del bloque de la constitucionalidad federal.

Séptima. Existe dentro del artículo primero de la Constitución Política de los Estados Unidos Mexicanos suficientes elementos para interpretar y construir la existencia de un bloque de la constitucionalidad en lo relativo a los derechos humanos.

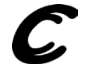

Fecha de recepción: 20 de febrero de 2015. Fecha de dictamen: 20 de marzo de 2015. 